\title{
Les Percières, Mariol
}

$n^{\circ} 6969$

\section{Olivier Troubat}

\section{(2) OpenEdition}

Journals

Édition électronique

URL : http://journals.openedition.org/adlfi/13435

ISSN : 2114-0502

Éditeur

Ministère de la culture

Référence électronique

Olivier Troubat, « Les Percières, Mariol », ADLFI. Archéologie de la France - Informations [En ligne], Auvergne, mis en ligne le 03 octobre 2014, consulté le 19 avril 2019. URL : http:// journals.openedition.org/adlfi/13435

Ce document a été généré automatiquement le 19 avril 2019

(C) Ministère de la Culture et de la Communication, CNRS 


\title{
Les Percières, Mariol
}

$\mathrm{n}^{\circ} 6969$

\author{
Olivier Troubat
}

Lien Atlas (MCC) : http://atlas.patrimoines.culture.fr/atlas/trunk/index.php?

ap_theme=DOM_2.01.02\&ap_bbox=3.462;46.008;3.525;46.043

1 Des pieux sont en cours de destruction par le courant de l'Allier, au lieu-dit des Percières, à Mariol (03). Leur dégagement s'opère dans une courbe extérieure, où le courant est très violent. Malgré un étiage exceptionnellement bas, au cours de l'été 2011, la zone est surcreusée par la rivière et il a fallu opérer un gros travail préalable de sécurisation du site, au moyen de boutes, de lignes de vie en aval, et de bateau et plongeurs de secours prêts à intervenir.

2 Six pieux de chêne sont visibles, sur une portée rectiligne de 9,80 m. Le fantôme de l'organisation restante montre un écartement moyen d'un pieu tous les $0,80 \mathrm{~m}$ à $1,10 \mathrm{~m}$. Le pieu en meilleur état conserve encore un diamètre de $0,23 \mathrm{~m}$. Un pieu est en cours de dégagement dans le talus de la rive. Du côté central de la rivière, le creusement est très important et seul un sabot métallique, usé, cassé et tordu par la rivière, a été retrouvé.

3 Une cartographie importante couvre la zone depuis le milieu du xVIII ${ }^{\mathrm{e}} \mathrm{s}$. apr. J.-C. L'emplacement est dans une zone inhabitée soumise aux crues, sur $800 \mathrm{~m}$ de large, où le lit de l'Allier a constamment changé d'emplacement. Milieu XVIII ${ }^{e}$ s. apr. J.-C. le site était ensablé sur la rive droite (est) de l'Allier. La rivière se déplace et le traverse entre 1791 et 1813 , le laissant par la suite sous les terres rive gauche (ouest). Le dégagement actuel et la remise en eau du site datent de seulement 2001.

La datation radiocarbone (Mariol Ma.1 - MKL $941: 40 \pm 30$. Probabilité 95,4 \%: 1690-1960 apr. J.-C.) témoigne des pollutions organiques de l'échantillon, en fonction des phases d'immersions et des phases terrestres. Les recherches en archives ont pu éliminer des plages de datation correspondant à des phases terrestres et cibler la période radiocarbone C14 appropriée, dans la fourchette 1690-1730. La typologie d'un sabot de pieu, découvert sur le site, correspond à cette période des $\mathrm{XVII}^{\mathrm{e}}-\mathrm{XVIII}{ }^{\mathrm{e}} \mathrm{s}$. apr. J.-C. 
5 Aucun lit cartographié depuis le milieu du XVIII ${ }^{\mathrm{e}}$ s. apr. J.-C. ne correspond à l'alignement de pieux. Par contre, un lit fossile antérieur lui coïncide, faisant passer l'Allier au nordouest et plaçant le site à droite du village de Mariol. Il pourrait répondre à l'emplacement et aux caractéristiques du quai d'un port fluvial, avec un alignement de solides pieux de chêne ferrés et enfoncés au mouton, et implantés pour durer. Des planches placées horizontalement sur champ l'une sur l'autre, ou des claies ou fascines, étaient alors calées entre les pieux et la rive afin de la soutenir.

6 Il pourrait s'agir du port de Mariol, fin XVII ${ }^{e}$ s. apr. J.-C. - début XVIII ${ }^{e}$ s. apr. J.-C., sachant que les ports fluviaux changent d'emplacement en fonction des changements de lits de la rivière. Ce petit port était alors l'un des 18 ports fluviaux sur l'Allier en Bourbonnais, dont la liste a été dressée en 1720, à l'occasion d'une enquête réalisée par les intendants du roi, sur la navigation fluviale de cette rivière.

INDEX

Index géographique : Auvergne, Allier (03), Mariol

operation Prospection sub-aquatique (PS)

Mots-clés : port fluvial, sabot, pieux

Index chronologique : XIXe siècle apr. J.-C., XVIIIe siècle apr. J.-C., XVIIe siècle apr. J.-C. 